\title{
Extracts of Calpurnia aurea leaves from southern Ethiopia attract and immobilise or kill ticks
}

\author{
A. Zorloni ${ }^{\mathrm{a}, \mathrm{c}}$, B.L. Penzhorn ${ }^{\mathrm{b}}$ and J.N. Eloff ${ }^{\mathrm{a}}$
}

${ }^{\text {a }}$ Phytomedicine Programme, Department of Paraclinical Sciences, Faculty of Veterinary Science, University of Pretoria, Private Bag X04, Onderstepoort, 0110, South Africa

${ }^{b}$ Department of Veterinary Tropical Diseases, Faculty of Veterinary Science, University of Pretoria, Private Bag X04, Onderstepoort, 0110, South Africa

${ }^{\mathrm{c}}$ Via Sempione 10, 28868 Varzo, Italy

\begin{abstract}
Calpurnia aurea extracts are used in southern Ethiopia to protect stock against ticks. Acetone, hexane and water leaf extracts of $C$. aurea collected in southern Ethiopia were tested for repellent/attractant and acaricidal properties on unfed adult Rhipicephalus pulchellus ticks. In contrast to many other plant species evaluated, C. aurea extracts did not have repellent properties, but rather had a slight attractant capacity. With $20 \%$ and $10 \%$ acetone extracts, all ticks were either killed or their mobility severely compromised after $1 \mu \mathrm{l}$ of extract was topically applied on the abdomen. At a $5 \%$ concentration, $85 \%$ of ticks were still affected. A $10 \%$ aqueous solution also had a marked effect. The results prove the efficacy of the traditional use of this extract and may lead to a product that can be used commercially to protect animals against tick infestation, under subsistence as well as industrialized conditions.
\end{abstract}

Keywords: Calpurnia aurea; Rhipicephalus pulchellus; Hexane; Acetone; Repellency bioassay; Toxicity bioassay; Traditional use

\section{Introduction}

Synthetic acaricides are the mainstay of tick control worldwide. Although acaricides are beneficial when properly used, misuse has led to poisoning of humans and animals (FAO, 1998) and to ticks developing resistance against certain compounds ( Ali and De Castro, 1993, De Castro and Newson, 1993, Regassa and De Castro, 1993 , Shiferaw et al., 1997 and Solomon and Kaaya, 1996 ). In Africa access to acaricides is curtailed by uncertain economic conditions, resulting in escalating prices of imported goods. Furthermore, incorrect administration of acaricides by 
untrained or unauthorised persons enhances development of resistance (Latif, 1992). If only synthetic acaricides are used, there is a risk that traditional knowledge of the use of indigenous plants could be lost. Reassessment of traditional knowledge of ethnoveterinary medicine is therefore justified (Zorloni, 2007).

Calpurnia aurea, a member of the subfamily Papilionoideae of the family Fabaceae (Coates Palgrave, 1983), is a plant commonly used in traditional medicine to treat diverse medical conditions and parasitic infestation, both in humans and animals (Hutchings, 1996). It is a small, multi-stemmed tree, 3-4 m tall, occurring widespread in bushland and grassland in sub-Saharan Africa and India. In southern Ethiopia, it is called cheka by the Borana people. It is often found in overgrazed areas and is easily cultivated (Germishuizen and Meyer, 2003 and Pooley, 1993). Extracts of C. aurea have been used in South Africa to treat maggot-infested wounds (Watt and Breyer-Brandwijk, 1962), and in Ethiopia to treat scabies (Jansen, 1981). In western Ethiopia, the juice of crushed leaves and bark is used for tick control (Regassa, 2000). The Borana people of northern Kenya and southern Ethiopia soak leaves of C. aurea in cold water to treat louse infestations in humans and calves (Heine and Brenzinger, 1988) and to control ticks on cattle (own observation). The plant is also used in Ethiopia to treat stomach disorders, amoebic dysentery and eye diseases (Abate, 1989). In southwestern Ethiopia, the leaves of C. aurea, mixed with other plant species, are crushed and squeezed to obtain a juice, which is applied through the auricular route for 2 days to treat earache in humans (Yineger and Yewhalaw, 2007). In the same area, the plant is traditionally used to treat rheumatism (Yineger et al., 2008). Antibacterial and antioxidant activity of C. aurea have been reported (Adedapo et al., 2008), and the plant has been used to treat bacterial dermatitis (Tadeg et al., 2005). It has also been used as a natural pesticide to improve grain storage (Blum and Bekele, 2002).

The main pharmacologically active compounds of $C$. aurea may be the alkaloid calpurmenin and its $13 \alpha-\left(2^{\prime}\right.$-pyrrolecarboxylic acid) ester (Vermin et al., 1979). The alkaloids virgiline and lupanine, as well as their carboxylic esters, have also been recorded (Van Wyk et al., 1991). As part of a larger ethnoveterinary survey to assess plants traditionally used for tick control in southern Ethiopia, we investigated the attractant/repellent and acaricidal effects of C. aurea extracts (Zorloni, 2007). Information on the reputed acaricidal properties of the plant was provided by a group of semi-nomadic pastoralists belonging to the Borana ethnic group. 


\section{Materials and methods}

C. aurea leaves were collected in September 2004 near Yabello, Ethiopia. The pastures were in very poor condition, due to the delayed onset of the rainy season, which was aggravated by the consequent overgrazing. C. aurea trees were among the very few plant species with a normal appearance.

To reduce possible contamination, especially by fungi, latex gloves were worn when leaves were collected. The plant material was spread out on paper sheets in the shade to dry. When desiccated, the leaves were stored in sealed containers, transferred to the laboratory and ground to a fine powder. It appears at least in some cases that properly dried plant leaves retain biological activity for periods close to 100 years (Eloff, 1999). The finely ground plant material (20 g) was suspended in $200 \mathrm{ml}$ of water, hexane or acetone (Eloff, 1998), and vigorously shaken for $20 \mathrm{~min}$. The supernatant was filtered through Whatman (number 1) filter paper. The filtrate was concentrated in a vacuum rotary evaporator and dried at room temperature. The dried extracts were then diluted in the same solvent used for extraction, at the concentrations required for the bioassays $(20 \%, 10 \%$, $5 \%$ and $1 \%)$.

As Rhipicephalus pulchellus is a common tick species on pasture in southern Ethiopia, unfed adult ticks of this species were selected for the bioassays. The ticks, stored in vials stoppered with cotton wool, were kept in a glass chamber closed by a removable cover, at an average temperature of $20 \pm 5{ }^{\circ} \mathrm{C}$. An average humidity of $80 \pm 10 \%$ was maintained by a saturated potassium chloride solution on the bottom of the chamber. The vials were set on a square glass plate, placed on four small bearings, so that the edges of the plate were $1.5 \mathrm{~cm}$ from the walls of the chamber. The potassium chloride solution also prevented ticks that escaped from the vials from leaving the plate. The bioassays were carried out at a room temperature of $20 \pm 5^{\circ} \mathrm{C}$ and humidity of $50 \pm 10 \%$. For both bioassays, 10 ticks were used for each of four replications.

\subsection{Repellency bioassay}

We used a technique developed in the Phytomedicine Programme (Nchu et al., 2005). Ten ticks were placed in the centre of a rectangular $(20 \mathrm{~cm} \times 5 \mathrm{~cm})$ polystyrene platform, fixed in the middle of a rectangular basin, which was filled with water almost to the upper surface of the platform, to prevent ticks escaping. At opposite sides of the platform, two glass rods were inserted, each fitted with a cylinder of Whatman (number 1) filter paper $(5 \mathrm{~cm} \times 3 \mathrm{~cm})$ over the glass rods at the top and at the bottom. The two filter paper cylinders of one rod were moistened with $1 \mathrm{ml}$ of the test 
solution (extract plus solvent), while the cylinders of the other rod were moistened with $1 \mathrm{ml}$ of the solvent only.

The experiment was based on the climbing behaviour of the ticks, which have a natural tendency to ascend grass stalks seeking a favourable position to find a vertebrate host (Nchu, 2004). This behaviour is maintained under laboratory conditions (Browning, 1976). The position of ticks was recorded four times, at 30 min intervals (Table 1).

Table 1. Results of the repellency bioassay. The four replications are shown in the first column, indicated by $R$ (=replication). The time of recording, i.e. every $30 \mathrm{~min}$, is reported in the second column. Then, the number of ticks present on the platform $(P)$ or on the two rods (test and control) is shown, with a specification regarding the position of the ticks ( $T$ = filter paper on the top of the rod; $M=$ middle part of the rod, not covered by filter paper; $B=$ filter paper on the bottom of the rod).

\begin{tabular}{|c|c|c|c|c|c|c|c|c|}
\hline \multirow{2}{*}{$\mathbf{R}$} & \multirow{2}{*}{ Time } & \multirow{2}{*}{$\mathbf{P}$} & \multicolumn{3}{|c|}{ Test } & \multicolumn{3}{|c|}{ Control } \\
\hline & & & $\mathbf{T}$ & $\mathbf{M}$ & $\mathbf{B}$ & $\mathbf{T}$ & $\mathbf{M}$ & $\mathbf{B}$ \\
\hline \multicolumn{9}{|c|}{ Calpurnia aurea (hexane 10\%) } \\
\hline \multirow[t]{4}{*}{1} & $30^{\prime}$ & 0 & 5 & 0 & 0 & 3 & 0 & 2 \\
\hline & $60^{\prime}$ & 0 & 4 & 1 & 0 & 3 & 0 & 2 \\
\hline & $90^{\prime}$ & 0 & 4 & 1 & 0 & 3 & 0 & 2 \\
\hline & $120^{\prime}$ & 0 & 4 & 1 & 0 & 3 & 0 & 2 \\
\hline \multirow[t]{4}{*}{2} & $30^{\prime}$ & 4 & 3 & 0 & 0 & 2 & 0 & 1 \\
\hline & $60^{\prime}$ & 3 & 3 & 0 & 0 & 3 & 0 & 1 \\
\hline & $90^{\prime}$ & 2 & 4 & 0 & 0 & 3 & 0 & 1 \\
\hline & $120^{\prime}$ & 2 & 4 & 0 & 0 & 3 & 0 & 1 \\
\hline \multirow[t]{4}{*}{3} & $30^{\prime}$ & 3 & 3 & 0 & 0 & 2 & 0 & 2 \\
\hline & $60^{\prime}$ & 3 & 3 & 0 & 0 & 2 & 0 & 2 \\
\hline & $90^{\prime}$ & 3 & 3 & 0 & 0 & 2 & 0 & 2 \\
\hline & $120^{\prime}$ & 3 & 3 & 0 & 0 & 2 & 0 & 2 \\
\hline 4 & $30^{\prime}$ & 1 & 6 & 1 & 0 & 1 & 0 & 1 \\
\hline
\end{tabular}




\begin{tabular}{|l|l|l|l|l|l|l|l|l|}
\hline R & Time & P & \multicolumn{2}{|l|}{ Test } & \multicolumn{3}{|l|}{ Control } \\
\hline & & & T & M & B & T & M & B \\
\hline & & & & & & & & \\
\hline & $60^{\prime}$ & 1 & 7 & 0 & 0 & 1 & 0 & 1 \\
\hline & $90^{\prime}$ & 1 & 7 & 0 & 0 & 1 & 0 & 1 \\
\hline & $120^{\prime}$ & 1 & 7 & 0 & 0 & 1 & 0 & 1 \\
\hline
\end{tabular}

\begin{tabular}{|l|l|l|l|l|l|l|l|l|}
\hline Tot. & $120^{\prime}$ & 6 & 18 & 1 & 0 & 9 & 0 & 6 \\
\hline & & & & 19 & & & 15 & \\
\hline
\end{tabular}

Repellency index: -12

\section{Calpurnia aurea (acetone 10\%)}

\begin{tabular}{|l|l|l|l|l|l|l|l|l|l|}
\hline 1 & $30^{\prime}$ & 5 & 4 & 0 & 0 & 0 & 0 & 1 \\
\hline & $60^{\prime}$ & 5 & 4 & 0 & 0 & 1 & 0 & 0 \\
\hline & $90^{\prime}$ & 3 & 5 & 0 & 0 & 2 & 0 & 0 \\
\hline & $120^{\prime}$ & 2 & 5 & 0 & 0 & 3 & 0 & 0 \\
\hline & $30^{\prime}$ & 4 & 3 & 0 & 1 & 2 & 0 & 0 \\
\hline & $60^{\prime}$ & 2 & 5 & 0 & 1 & 2 & 0 & 0 \\
\hline & $90^{\prime}$ & 1 & 5 & 0 & 1 & 3 & 0 & 0 \\
\hline & $120^{\prime}$ & 1 & 5 & 0 & 1 & 3 & 0 & 0 \\
\hline 3 & $30^{\prime}$ & 2 & 2 & 0 & 2 & 2 & 0 & 2 \\
\hline & $60^{\prime}$ & 1 & 4 & 1 & 0 & 2 & 0 & 2 \\
\hline & $90^{\prime}$ & 1 & 4 & 1 & 0 & 2 & 0 & 2 \\
\hline & $120^{\prime}$ & 1 & 4 & 1 & 0 & 2 & 0 & 2 \\
\hline & $30^{\prime}$ & 5 & 3 & 1 & 0 & 1 & 0 & 0 \\
\hline & $60^{\prime}$ & 3 & 4 & 0 & 0 & 2 & 0 & 1 \\
\hline & $90^{\prime}$ & 3 & 4 & 0 & 0 & 2 & 0 & 1 \\
\hline
\end{tabular}




\begin{tabular}{|l|l|l|l|l|l|l|l|l|}
\hline R & Time & P & \multicolumn{2}{|c|}{ Test } & \multicolumn{3}{|l|}{ Control } \\
\hline & & & T & M & B & T & M & B \\
\hline & $120^{\prime}$ & 3 & 4 & 0 & 0 & 2 & 0 & 1 \\
\hline Tot. & $120^{\prime}$ & 7 & 18 & 1 & 1 & 10 & 0 & 3 \\
\hline & & & & 20 & & & 13 & \\
\hline & \multicolumn{7}{|c|}{} \\
\hline \multicolumn{8}{|c|}{ Repellency index: -21 } \\
\hline
\end{tabular}

\subsection{Toxicity bioassay}

Because of its intrinsic toxicity, hexane extracts were not used in this bioassay. In previous experiments, acetone was toxic when ticks were immersed in it (Chagas et al., 2003 , Freitas and Fernandes, 2005 and Gonçalves et al., 2007 ), but not when topically applied ( Williams, 1993, Porter et al., 1995 and Nchu et al., 2005 ). No ticks showed any negative effects when $1 \mu$ of acetone was applied in our preliminary experiments.

One $\mu \mathrm{l}$ of test solution (water or acetone extract) was placed onto each of 10 ticks set in a Petri dish. With the acetone extract, the assay was repeated with solutions at concentrations of $20 \%$, $10 \%, 5 \%$ and $1 \%$ of the extract. There were four replicates using a total of 40 ticks for each solution. A $10 \%$ solution of the water extract was also used. After application of the test solution, the ticks were placed in a glass vial with a stopper allowing normal air exchange. The mortality rate was recorded after $24 \mathrm{~h}$. Ticks were classified in four classes: normal (N), weak (W) when showing moderate difficulty in moving, very weak (VW) if showing an incoordination of movement making them unable to walk, dead (D) when not responding to human breath after $30 \mathrm{~s}$.

\section{Results}

\subsection{Repellency bioassays}

Virtually all movement of ticks occurred in the first and second 30-min intervals, with only a few movements recorded subsequently. This probably indicates the volatility of the compounds responsible for attraction or repellency. As the ticks generally aggregated at the top of the rods, we disregarded the differences of position (top or bottom), but considered only the total number of ticks settled on each rod. 
The results are expressed by a repellency index (R.I.) calculated using the formula $\left[\left(N_{\mathrm{c}}-N_{\mathrm{t}}\right) /\left(N_{\mathrm{c}}+N_{\mathrm{t}}\right)\right] \times 100$, where $N_{\mathrm{c}}$ refers to the number of ticks on the control rod and $N_{\mathrm{t}}$ to the number of ticks on the test rod ( Pascual-Villalobos and Robledo, 1998 and Lwande et al., 1999). Both the hexane and acetone extracts gave negative results, with repellency indexes (approximated to the whole closest numbers), of -12 and -21 , respectively (Table 1). With hexane extracts, the distribution of the ticks on the two glass rods appears rather similar in the first three replications, while in the fourth the ticks seemed to prefer the glass rod covered with filter paper impregnated with the test solution. In the bioassays with acetone extracts, the distribution of the ticks was similar in all four replications, with a slight preference for the rod with the test solution.

\subsection{Toxicity bioassays}

Even though the number of dead ticks was never very high with acetone extracts (Table 2), all surviving ticks at concentrations of $20 \%$ and $10 \%$ had pronounced weakness and incoordination of movement, making them unable to walk. Affected ticks remained stationary, as limb movements were incoordinated. At a concentration of $5 \%$, these effects were also observed for 34/40 surviving ticks and some signs of impaired movement were shown by the remaining six. Even at a concentration of $1 \%$, movement was affected in $8 / 39$ surviving ticks.

Table 2. Results of the toxicity bioassay. The concentrations (\%) are shown in the first column, while the number of replication (R), i.e. 4 for each concentration, is shown in the second column. The number of ticks classified as normal $(N)$, weak (W), very weak (VW) or dead (D) is also reported. On the right side of the table, the percentage of the ticks decidedly affected (i.e. dead plus very weak) is shown for each replication (\%DA), as well as for the total of the four replications performed for each concentration (T\%DA).

\begin{tabular}{|l|l|l|l|l|l|l|l|}
\hline$\%$ & $\mathbf{R}$ & $\mathbf{N}$ & $\mathbf{W}$ & $\mathbf{V W}$ & $\mathbf{D}$ & $\mathbf{\% D A}$ & T\%DA \\
\hline \multicolumn{7}{|c|}{ C. aurea (acetone extracts) } \\
\hline 20 & 1 & 0 & 0 & 6 & 4 & 100 & 100 \\
\hline & 2 & 0 & 0 & 2 & 8 & 100 & \\
\hline & 3 & 0 & 0 & 3 & 7 & 100 & \\
\hline & 4 & 0 & 0 & 9 & 1 & 100 & \\
\hline & & & & & & \\
\hline 10 & 1 & 0 & 0 & 7 & 3 & 100 & 100 \\
\hline & 2 & 0 & 0 & 6 & 4 & 100 & \\
\hline
\end{tabular}




\begin{tabular}{|c|c|c|c|c|c|c|c|}
\hline \multirow[t]{3}{*}{$\%$} & $\mathbf{R}$ & $\mathbf{N}$ & W & VW & D & $\% D A$ & T\%DA \\
\hline & 3 & 0 & 0 & 8 & 2 & 100 & \\
\hline & 4 & 0 & 0 & 7 & 3 & 100 & \\
\hline \multirow[t]{4}{*}{5} & 1 & 0 & 0 & 10 & 0 & 100 & 85 \\
\hline & 2 & 0 & 2 & 8 & 0 & 80 & \\
\hline & 3 & 0 & 3 & 7 & 0 & 70 & \\
\hline & 4 & 0 & 1 & 9 & 0 & 90 & \\
\hline \multirow[t]{4}{*}{1} & 1 & 10 & 0 & 0 & 0 & 0 & 2.5 \\
\hline & 2 & 5 & 5 & 0 & 0 & 0 & \\
\hline & 3 & 6 & 3 & 0 & 1 & 10 & \\
\hline & 4 & 10 & 0 & 0 & 0 & 0 & \\
\hline \multicolumn{8}{|c|}{ C. aurea (water extracts) } \\
\hline \multirow[t]{4}{*}{10} & 1 & 2 & 2 & 6 & 0 & 60 & 50 \\
\hline & 2 & 2 & 5 & 3 & 0 & 30 & \\
\hline & 3 & 5 & 1 & 4 & 0 & 40 & \\
\hline & 4 & 1 & 2 & 7 & 0 & 70 & \\
\hline
\end{tabular}

Although none of the ticks exposed to the 10\% water extract died, 20/40 were severely affected and 10/40 were mildly affected.

\section{Discussion}

The results of these bioassays with C. aurea leaf extracts indicate absence of repellency or even mild attraction. Of a large number of plant extracts evaluated ( Nchu, 2004 and Zorloni, 2007 ) this is one of few that appears to attract the ticks. While it is clear that both hexane and acetone $C$. aurea extracts at a $10 \%$ concentration did not have repellent properties, further work is needed to confirm that these extracts have an attraction for ticks. Possible attraction could be due, for instance, to the brilliant green colour of the C. aurea leaf extracts (especially in acetone) as well as to other factors, or a combination of these. 
The toxicity of such a small volume of the acetone or water extract on the ticks holds much promise for the practical use of these extracts. If $1 \mu \mathrm{l}$ of a $10 \%$ water extract affected the ticks severely, drenching them with a water extract would probably kill them outright. The fact that aqueous extracts of $C$. aurea leaves are also toxic has important implications for field application of tick control by rural pastoralists. This may explain the importance given to the plant by the Borana people. The potential of $C$. aurea for tick control is enhanced by its wide occurrence in Africa and its capacity to resist drought and overgrazing. This makes it available throughout the year without risk of excessive exploitation and environmental degradation. As C. aurea is easy to cultivate, its potential value to semi-nomadic pastoralists as well as to commercial stock farmers is further enhanced.

Further work could evaluate the effect of water extracts on different ticks species and the effect of the water extracts on the stock animals. The stability and human toxicity of the extracts should also be considered. A next step should be isolation and characterisation of the active compounds. For practical purposes in poor communities, the optimal extracting capacity of water should be determined by investigating different approaches, for instance addition of readily available natural or synthetic products (animal urine, soap, petrol, etc.), by using warm water, or by modifying the extraction time and the concentration of plant material.

Specific field trials should be conducted, in order to set up efficient programmes of tick control based on optimal concentration of the products, and frequency of application in different seasons. The environmental toxicity of $C$. aurea extracts should also be investigated, in addition to environmental, practical and economic aspects of its exploitation. Finally, rational reinforcement of a traditional practice can result in a strengthening of the community web in nomadic societies, which are currently submitted to social disruption.

\section{Acknowledgements}

In the first place we thank the rural people from the various communities of southern Ethiopia who shared their valuable knowledge. Special thanks are due to Dr Steve R. Magano, University of Limpopo, who provided the ticks used in the assays as well as the chamber for their maintenance. We also thank Felix Nchu, Ato Abdulkadir Osman, Ato Emanuel Boru, Ato Abdurahman Abdullahi Abdi, Dr Merkeb Belay Gemta, Dr Abayeneh Dagne, Dr Solomon Gebre and Dr John Githiori for fruitful discussions and collaboration. The National Research Foundation in South Africa provided funding to the Phytomedicine Programme (www.up.ac.za). 
This project (V062/04) was approved by the Research Committee of the Faculty of Veterinary Science and the Animal Use and Care Committee of the University of Pretoria.

\section{References}

Abate, 1989 G. Abate In: S. Demissew, Editor, Etse Debdade: Ethiopian Traditional Medicine, Addis Ababa University Press, Addis Ababa (1989).

Adedapo et al., 2008 A.A. Adedapo, F.O. Jimoh, S. Koduru, A.J. Afolayan and P.J. Masika, Antibacterial ant antioxidant properties of the methanol extracts of the leaves and stems of Calpurnia aurea, BMC Complement. Altern. Med. 1 (8) (2008), p. 53.

Ali and De Castro, 1993 M. Ali and J.J. De Castro, Host resistance to ticks (Acari: Ixodidae) in different breeds of cattle at Bako, Ethiopia, Trop. Anim. Health Prod. 25 (1993), pp. 215-222.

Blum and Bekele, 2002 A. Blum and A. Bekele, Storing grains as a survival strategy of small farmers in Ethiopia, J. Int. Agric. Ext. Ed. 9 (2002), pp. 77-83.

Browning, 1976 T.O. Browning, The aggregation of questing ticks, Rhipicephalus pulchellus, on glass stems, with observations on R. appendiculatus, Phys. Entomol. 1 (1976), pp. 107-114.

Chagas et al., 2003 A.C.S. Chagas, R.C. Leite, J. Furlong, H.T. Prates and W.M. Passos, Sensibilidade do carrapato Boophilus microplus a solventes, Ciência Rural 33 (2003), pp. 109114.

Coates Palgrave, 1983 K. Coates Palgrave, Trees of Southern Africa (2nd ed.), Struik Publishers, Cape Town (1983).

De Castro and Newson, 1993 J.J. De Castro and R.M. Newson, Host resistance in cattle tick control, Parasitol. Today 9 (1993), pp. 13-17.

Eloff, 1998 J.N. Eloff, Which extractant should be used for the screening and isolation of antimicrobial components from plants?, J. Ethnopharmacol. 60 (1998), pp. 1-8. 
Eloff, 1999 J.N. Eloff, It is possible to use herbarium specimens to screen for antibacterial components in some plants, J. Ethnopharmacol. 67 (1999), pp. 355-360.

FAO, 1998 FAO - Food and Agriculture Organization, 1998. Regional Coordination for the Integrated Tick and Tick. Borne Disease Control Programme in Eastern, Central and Southern Africa. Report for the OAU/IBAR - Organization of Africa Unit/Inter-Bureau for Animal Resources.

Freitas and Fernandes, 2005 Freitas, E.P.S., Fernandes, F.F., 2005. Estudo da bioatividade larvicida das plantas Stryphnodendron adstringens, Qualea grandiflora e Copaifera langsdorffii para o controle de Boophilus microplus (Canestrini, 1887) (Acari, Ixodidae). In: Congresso de Pesquisa, Ensino e Extensão da UFG-CONPEEX. Anais Eletrônicos do XIII Seminário de Iniciação Cientifica.

Germishuizen and Meyer, 2003 In: G. Germishuizen and N.L. Meyer, Editors, Plants of Southern Africa: An Annotated Checklist. Strelitzia 14, National Botanical Institute, Pretoria (2003).

Gonçalves et al., 2007 K. Gonçalves, E. Toigo, B. Ascoli, G. von Poser and V.L. Sardá Ribeiro, Effects of solvents and surfactant agents on the female and larvae of cattle tick Boophilus microplus, Parasitol. Res. 100 (2007), pp. 1267-1270.

Heine and Brenzinger, 1988 Heine, B., Brenzinger, M., 1988. Plant concepts and plant use. An ethnobotanical survey of the semi-arid and arid lands of East Africa. Part 4. Plant of the Borana (Ethiopia and Kenya) 296 p., Band 9 - Kölner Beiträge zur Entwicklungsländerforschung /Cologne Development Studies. Verlag Breitenbach Publishers, Saarbrücken, Fort Lauderdale.

Hutchings, 1996 A. Hutchings, Zulu Medicinal Plants, An Inventory, University of Natal Press, Pietermaritzburg (1996).

Jansen, 1981 P.C.M. Jansen, Spices, Condiments and Medicinal Plants in Ethiopia, Their Taxonomy and Agricultural Significance, Centre for Agricultural Publishing and Documentation, Wageningen (1981). 
Latif, 1992 A.A. Latif, Sustainable control methods for ticks and tickborne diseases in Africa. In: J.A. Kategile and S. Mubi, Editors, Future of Livestock Industries in East and Southern Africa, ILRI - International Livestock Centre for Africa, Addis Ababa (1992).

Lwande et al., 1999 W. Lwande, A.J. Ndakala, A. Hassanali, L. Moreka, E. Nyandat, M. Ndungu, H. Amiani, P.M. Gitu, M.M. Malonza and D.K. Punyua, Gynandropsis ginandra essential oil and its constituents as tick (Rhipicephalus appendiculatus) repellents, Phytochemistry 50 (1999), pp. 401-405.

Nchu, 2004 Nchu, F., 2004. Developing methods for the screening of ethnoveterinary plants for tick control. MSc Thesis. Medical University of South Africa.

Nchu et al., 2005 F. Nchu, S.R. Magano and J.N. Eloff, In vitro investigation of the toxic effects of extracts of Allium sativum bulbs on adults of Hyalomma marginatum rufipes and Rhipicephalus pulchellus, J. S. Afr. Vet. Assoc. 76 (2005), pp. 99-103.

Pascual-Villalobos and Robledo, 1998 M.J. Pascual-Villalobos and A. Robledo, Screening for anti-insect activity in Mediterranean plants, Ind. Crop Prod. 8 (1998), pp. 183-194.

Pooley, 1993 E. Pooley, The Complete Field Guide to Trees of Natal, Zululand and Transkei, Natal Flora Publications Trust, Natal Herbarium, Durban (1993).

Porter et al., 1995 R.B.R. Porter, P.B. Reese and L.A.D. Williams, Acaricidal and insecticidal activities of Candina-4,10(15)-dien-3-one, Phytochemistry 40 (1995), pp. 735-738.

Regassa, 2000 A. Regassa, The use of herbal preparations for tick control in western Ethiopia, J. S. Afr. Vet. Assoc. 71 (2000), pp. 240-243.

Regassa and De Castro, 1993 A. Regassa and J.J. De Castro, Tick resistance to acaricides in western Ethiopia, Trop. Anim. Health Prod. 25 (1993), pp. 69-74. 
Shiferaw et al., 1997 Y. Shiferaw, A. Girma, Y. Jober, M. Haile Mariam and E. Zerbini, Bioassay of acaricide resistance on three common cattle tick species around Holeta area, Proceedings of the 5th National Conference of the Ethiopian Society of Animal Production Addis Ababa (1997), pp. $146-156$.

Solomon and Kaaya, 1996 G. Solomon and G.P. Kaaya, Comparison of resistance in three breeds of cattle against African ixodid ticks, Exp. Appl. Acarol. 20 (1996), pp. 223-230.

Tadeg et al., 2005 H. Tadeg, E. Mohammed, K. Asres and T. Gebre-Mariam, Antimicrobial activities of some selected traditional Ethiopian medicinal plants used in the treatment of skin disorders, J. Ethnopharmacol. 100 (2005), pp. 168-175.

Van Wyk et al., 1991 B.E. Van Wyk, G.H. Verdoorn, R. Greinwald and P. Bachmann, Taxonomic significance of major alkaloids in the genus Priestleya, Biochem. Syst. Ecol. 19 (1991), pp. 595598.

Vermin et al., 1979 W.J. Vermin, A.J. de Kok, C. Romers, M.H. Radema and J.L. van Eijk, Calpurmenin and ist 13a-(2'-pyrrolecarboxylic acid) ester, Acta Crystallogr. 35 (1979), pp. 18391842.

Watt and Breyer-Brandwijk, 1962 J.M. Watt and M.G. Breyer-Brandwijk, The Medicinal and Poisonous Plants of the Southern and Eastern Africa (2nd ed.), Livingstone, London (1962).

Williams, 1993 L.A.D. Williams, Adverse effects of extracts of Artocarpus altilis Park. and Azadirachta indica (A. Juss) on the reproductive physiology of adult female tick, Boophilus microplus (Canest.), J. Inver. Reprod. Dev. 23 (1993), pp. 159-164.

Yineger and Yewhalaw, 2007 H. Yineger and D. Yewhalaw, Traditional medicinal plant knowledge and use by local healers in Seroku District, Jimma Zone, Southwestern Ethiopia, J. Ethnobiol. Ethnomed. 3 (1) (2007), p. 24. 
Yineger et al., 2008 H. Yineger, D. Yewhalaw and D. Teketay, Ethnomedicinal plant knowledge and practice of the Oromo ethnic group in southwestern Ethiopia, J. Ethnobiol. Ethnomed. 4 (1) (2008), p. 11.

Zorloni, 2007 Zorloni, A., 2007. Evaluation of plants used for the control of animal ectoparasitoses in southern Ethiopia (Oromiya and Somali regions). MSc Thesis. Phytomedicine Programme, University of Pretoria. 